\title{
INTEMPÉRIES AO EXERCÍCIO DO ACESSO À INFORMAÇÃO E AO CONTROLE SOCIAL DIANTE DE UM ESTADO PÓS-DEMOCRÁTICO
}

\author{
LOPES, A. I.1; BITTENCOURT, C. M. ${ }^{2}$
}

PALAVRAS-CHAVE: Informação. Controle Social. Pós-democracia. Pós-verdade. Neoliberalismo.

\section{RESUMO}

As transformações ocorridas nas democracias contemporâneas marcam uma possível mudança no papel do Estado, notadamente não tanto na perspectiva formal, mas especialmente na material, razão pela qual tem-se referido como Estado Pós Democrático de Direito. Nesse sentido, um dos fenômenos que marcam essa transição é o da Pós-verdade, constituindo uma verdadeira ameaça à democracia e suas instituições. Uma vez que a premissa central do Estado Democrático de Direito é a possibilidade de acesso à informação a fim de viabilizar a participação e controle social sobre os atos da administração pública, o problema que permeia a presente investigação é: quais os desafios do acesso à informação e o exercício do controle social em uma sociedade marcada pela pós-verdade? Sendo que o objetivo é conhecer quais as possibilidades do acesso à informação e as consequências que podem advir ao controle social em uma sociedade que se constitui de verdades escolhidas e decisões que se afastam da busca pela razão. Para atingir este objetivo o trabalho utilizará do método dialético, e como metodologia de pesquisa a bibliográfica. Desta forma o presente artigo abordará em dois tópicos, sendo que no primeiro explana acerca do acesso à informação e da participação social para a concretização do controle social, e em um segundo momento sobre como a pós-verdade se torna um entrave ao controle social e ao acesso à informação. Pode-se concluir a partir do trabalho desenvolvido que as crenças que os indivíduos têm como razão e como certas, que nada mais são que pseudoverdades, e são disseminadas como verídicas, geram a outros cidadãos a percepção de veracidade do que está sendo disseminado, de forma que estes dados se tornam parte de uma desinformação generalizada pelo público, obstruindo a possibilidade de que o cidadão tenha acesso a informações corretas mediante o controle social e que a partir delas possa agir para buscar melhorias do Estado.

\section{OBSTACLES TO THE EXERCISE ACESS OF INFORMATION AND SOCIAL CONTROL IN A POST- DEMOCRATIC STATE}

Keywords: Information. Social Control. Post-democracy. Post-truth. Neoliberalism.

\section{ABSTRACT}


The transformations that have been occurring in contemporary democracies mark a possible change in the role of the State, notably not so much from a formal perspective, but especially from a material perspective, which is why it has been referred to as the Post-Democratic State of Law. In this sense, one of the phenomena that mark this transition is that of the Post-truth, constituting a real threat to democracy and its institutions. Since the central premise of the Democratic Rule of Law is the possibility of access to information in order to enable participation and social control over the acts of public administration, the problem that permeates the present investigation is: what are the challenges of access to information and the exercise of social control in a society marked by the post-truth? Being that the objective is to know what are the possibilities of access to information and the consequences that can come to social control in a society that consists of chosen truths and decisions that deviate from the search for reason. To achieve this goal, the work will use the dialectical method, and the bibliographic research methodology. Thus, this article will address two topics, the first explaining about access to information and social participation for the realization of social control, and the second about how the post-truth becomes an obstacle to social control and access to information. It can be concluded from the work developed that the beliefs that individuals have as reason and as certain, that they are nothing but pseudo-truths, and are disseminated as true, generate to other citizens the perception of veracity of what is being disseminated, of so that these data become part of a widespread misinformation by the public, obstructing the possibility that the citizen has access to correct information through social control and that from it can act to seek improvements of the State.

\section{INTRODUÇÃO}

A partir das mudanças vivenciadas atualmente, a sociedade vai em direção a outra forma de democracia, intitulada pós-democracia que se distância dos objetivos e fundamentos que constitui um Estado Democrático de Direito, como a concretização dos direitos fundamentais e sociais. Simultaneamente cresce o discurso neoliberal, em que a garantia de direitos fundamentais é vista como um "fardo" ou um "entrave" ao desenvolvimento do Estado, das Instituições, mas especialmente, do mercado.

Juntamente com a pós-democracia é possível notar a pós-verdade, que seria uma forma de compreensão da verdade (pseudoverdade) apenas no conceito de um indivíduo, não reconhecendo qualquer pressuposto -até mesmo cientifico ou com bases verossímeis- que não se aderem às suas crenças ou egocentrismo.

Nesse contexto, busca-se conhecer como se insere a possibilidade de acesso à informação pela sociedade quando há informações distorcidas sendo disseminadas. Procurando neste trabalho tecer as complexidades que decorrem dessa conjuntura ao controle social, uma vez que é baseado nas informações que a população detém do poder público. E quando estas informações são distorcidas prejudica o efetivo controle social, levando a um ciclo em que informações incorretas retiram a possibilidade de participação social da população na Administração Pública.

O estudo tem como objetivo verificar os obstáculos ao exercício do controle social sobre a Administração Pública, compreendendo os problemas que geram da desinformação, e do contexto de que crenças possuem maior veridicidade que fatos. 
0 problema de pesquisa consiste em: como se dará o acesso à informação e o exercício do controle social em uma sociedade que atende as razões da pós-verdade? Quais os desafios do acesso à informação e do exercício do controle social em uma sociedade marcada pela pós-verdade?

Como hipótese de pesquisa é possível compreender que as pseudoverdades difundidas irão prejudicar o controle social, vez que a sociedade não terá como fazer um juízo de valor correto para entender as ações da Administração Pública e requerer aquilo que é necessário à população, simultaneamente concluindo que o poder público não lhe representa.

Como método de pesquisa utiliza-se o método dialético em que parte-se do debate de que a pós-verdade pode estar comprometendo a possibilidade de acesso à informação, e assim limitando um controle social efetivo sobre o poder público, e como metodologia tem-se a pesquisa bibliográfica.

Para tanto o presente trabalho discorrerá preliminarmente sobre o acesso à informação e o exercício do controle social na busca por uma gestão pública mais eficiente.

Em um segundo momento o trabalho perquire por conhecer os pressupostos da pós-democracia e compreender a forma com a pós-democracia e a nova razão neoliberal traz a pós-verdade e corrompe as formas de acesso à informação.

\section{O ACESSO À INFORMAÇÃO PARA A PARTICIPAÇÃO E O EXERCÍCIO DO CONTROLE SOCIAL}

Informação é acima de tudo poder, tanto o é que Salgado (2012) define que por muito tempo os Estados foram marcados pela inacessibilidade de seus dados e o silêncio sobre as informações públicas.

Abramo (2008) disserta que isto ocorre devido a uma potencialidade muito simples: porque o poder político é dependente do acesso à informação principalmente numa conjuntura da Sociedade da Informação, e nesse contexto que aquele que possuir maior gama de informações tem preferência em alcançar o objetivo pretendido, isto sendo um Estado, uma empresa, ou até mesmo a sociedade.

$\mathrm{Na}$ esfera da sociedade atual é indiscutível a necessidade inerente de acesso à informação, visto que se trata de um interesse para uma pluralidade, assim afirma Jardim (1999) que a informação possui um campo de atuação tão amplo porque é esta que dá o alcance para a sociedade ter soberania sobre a Administração Pública.

A tomada de conhecimento dos dados públicos é o que definirá a escolha do cidadão, quanto maior o número de informações existentes para exercer uma escolha maior a possibilidade de acerto. Canela e Nascimento (2009) corroboram essa assertiva tomando como exemplo a eleição de um prefeito, que teve como principal meta de campanha a construção de novas escolas para um determinado município, quando há a eleição do prefeito e este é empossado no cargo relata que não haverá possibilidade de construir as escolas porque o município não possui recursos para esse empreendimento, a questão que suscita dúvidas aos autores é se estes habitantes do município teriam essas informações, para que tivessem as próprias conclusões.

Assim, há a relevância na articulação da sociedade frente aos governantes, em um conceito trazido por alguns doutrinadores de assimetria de informação. Araujo e Sanches (2005) discorrem que o problema se insere no quesito em que há duas partes e estas não possuem o mesmo nível de conhecimento, o que vem a gerar uma desvantagem a parte que não possui a compreensão do todo informacional. 
É visível que essa falta de informação sempre imporá dificuldades aos cidadãos, porque toda a análise baseada em falta de informações é perniciosa. Saito (2016) desenvolve que no conceito de voto, em que o eleitor não tem uma base de informações para que possa compreender o mandato de um governante, resulta que o cidadão-eleitor não terá como premiar o governante votando novamente na próxima eleição, ou ao contrário punilo pelos atos que não foram satisfatórios ao interesse da comunidade mediante políticas públicas durante o período do governante.

Como observa Bitencourt e Reck (2015, p. 98) uma administração que tem transparência em seus atos possibilita a participação do cidadão na gestão e controle, sendo que "para que essa expectativa se torne realidade, é essencial que se tenha capacidade de conhecer e compreender as informações divulgadas".

0 acesso à informação é a melhor forma de viabilizar a atuação do cidadão perante o governo, visto que a informação não é o instrumento para a atuação, mas sim sua condição para que haja o exercício. É apenas com a quantidade e qualidade de informação correta que os cidadãos poderão opor-se as realizações do governo, Jardim (1999) aponta que a repercussão e a posse da informação são os semblantes para a participação da sociedade.

As consequências de haver uma baixa difusão de informações para a sociedade, é que muitas vezes devido ao não conhecimento acerca das formas de atuação da Administração Pública pode haver uma apatia da população sobre a forma com o que o governo está sendo administrado, e devido a essa ausência da população pode haver facilidades na má gestão pública, possibilitando a ocorrência inclusive de improbidades administrativas.

Segundo Prata (2007, p. 22) a apatia levaria a uma ausência de controle sobre os atos do Estado, e disserta ainda que essa inexistência de controle sobre a Administração Pública geraria "um ciclo que termina por realimentar e ampliar a aludida assimetria informacional".

0 controle realizado sobre os atos do poder público pela população denomina-se controle social e participação popular, e consoante Siraque (2004) o controle social pode ser definido como a verificação das decisões e a fiscalização da execução dessas decisões. Em síntese, submeter o Estado ao cidadão que controla os atos públicos, enquanto a participação popular corrobora para formar normas.

Secchin (2008) define que o controle social seria a participação da sociedade na observação da Administração Pública, entrando na esfera das políticas públicas, na gestão das condutas, por fim seria a participação em todas as áreas que afetassem o bem-estar da sociedade.

Já Bitencourt e Reck (2015) definem a participação popular como sendo um momento em que a Administração Pública irá interagir com as demais esferas públicas para a realização da tomada de decisão. E o controle social ocorreria após o processo de decisão, para averiguar se as decisões foram realizadas da forma que deveriam, e se houve as concretizações da tomada de decisão.

Corrobora Secchin (2009) que quando há o controle da gestão pela sociedade é indubitável a melhoria que alcança no setor público de forma que os atores responsáveis pelo governo terão melhores práticas de governança, e alcançarão uma diminuição de desvios e abusos na utilização da coisa pública.

É correto afirmar que há diversas formas de controle da Administração Pública, controles que são direcionados a pretensão de fazer com que a sociedade possa supervisionar as gestões e colocar em pauta as políticas públicas que perceba necessárias. Para Barcelos (2008) é assim que surgem inúmeras dúvidas quanto 
ao regular contexto do controle, porque é impossível a população concordar ou discordar de determinada política quando não a conhece.

De maneira que se percebe a necessidade de exercer o controle para a melhoria da máquina pública, segundo Bitencourt e Reck (2015) cria-se um ciclo vicioso de que apenas com informação de qualidade que poderá haver o controle exercido pela sociedade em face ao governo, e apenas com controle é que poderá haver uma forte publicidade dos atos públicos. Uma vez que é com a qualidade da informação prestada que se realiza a conexão entre a administração e os administrados.

No tópico seguinte procura-se demonstrar as mudanças e óbices que o Estado Pós-Democrático trouxe a possibilidade do acesso à informação e do controle social, representando como a população vem baseando suas informações em crenças.

\section{A PÓS-VERDADE E OS DESAFIOS AO ACESSO À INFORMAÇÃO, PARTICIPAÇÃO E EXERCÍCIO DO CONTROLE SOCIAL}

Toby Mendel (2009, p. 32) traça alguns conceitos sobre as leis de informação mundiais enfatizando a importância de um livre fluxo de informações que deveria ser oportunizado a sociedade, sendo definido pelo autor que informação seria o "oxigênio para a democracia", e parte desse contexto para determinar a importância da informação para a sociedade.

Sant'Anna (2008, p. 21) define que quando da abertura da informação para a população cria-se um controle que levaria a diminuição das causas de "clientelismo, corrupção, emprego de recursos públicos em favor de minorias privilegiadas". Definindo que essa possibilidade de análise das atividades públicas se correlaciona amplamente com a transparência do Estado.

Conforme leciona Sant'Anna (2008) essas atividades que denigrem a sociedade geram uma forma de ceticismo da população que se torna descrente nas ações da Administração, e assim tendem a se afastar dos espaços de observação pública, o que viabilizará que mais ações incorretas possam continuar acontecendo, deturpando completamente a forma da democracia a qual tem por primazia o interesse da maioria.

Tanto o é que no Estado Democrático de Direito se insere o quadro do cidadão realizando a gestão e o controle da Administração Pública, e para Di Pietro (2016) a participação popular no governo seria uma característica fundamental do Estado Democrático de Direito, justamente por diminuir as diferenças entre Estado e indivíduo, realizando uma aproximação entre o governo e os administrados.

Bitencourt e Reck (2015) determinam que partir do controle social exercido frente a audiências públicas, orçamentos participativos e conselhos municipais pode haver um ambiente propício ao controle social e a participação social, visto que ambos são importantes formas de comunicação da sociedade com o poder público. Fagundes (2015) corrobora sobre a necessidade de fiscalização por parte da população, construindo que as medidas que são realizadas pela Administração Públicas necessitam ser vistas pela sociedade, porque é justamente quem tem que fiscalizar os atos, avaliando se os gastos, a realização realmente condiz com a política que o governo está adotando.

Entretanto o acesso à informação e o controle social passam por uma fase de mudanças, pois até mesmo a forma do Estado Democrático de Direito está em transição. Inicialmente consta-se as contribuições trazidas 
pelo sociólogo sueco Zigmunt Bauman sobre a nova vestimenta do Estado, que define como sendo um novo momento vivenciado pela sociedade, nomeando de pós-modernidade. Bauman (2001) disserta que nesse momento as bases que antes eram sólidas já não existem mais ou não podem mais explicar o momento que vivemos, nesse estágio a liquidez se refere à fluidez, tudo acontece de forma muito rápida sem ter a prisão quando a padrões que eram delimitados anteriormente.

No entanto a pós-modernidade trazida por Bauman já flui em sua concepção de liquidez e dá espaço a uma nova ótica de governo, a denominada pós-democracia.

Assim enquanto a pós-modernidade seria caracterizada por tempos de incerteza, para Casara (2017) na pós-democracia há um quadro em que ainda possuímos a fachada de um Estado Democrático de Direito, mas internamente há mudanças ocorrendo, uma vez que o que está sendo retirado da sociedade são os valores democráticos presentes no Estado Democrático de Direito, perdas estas que são apresentadas apenas como uma crise que está ocorrendo ao Estado.

Casara (2017, p. 16) define o modelo pós-democrático, como sendo o "Estado sem limites rígidos ao exercício do poder, isso em um momento em que o poder econômico e o poder político se aproximam e quase voltam a se identificar, sem pudor". 0 autor refere que a democracia já é apenas uma simulação do que era, já que os princípios que a norteavam não a compõem mais.

Já Ballestrin (2018) compreende o conceito de pós-democracia como uma ligação entre política e economia, determinando a diminuição da política e o fortalecimento da economia, sendo assim uma disputa da sociedade e da democracia, na sua condição de povo e de outro lado o neoliberalismo na constituição de uma elite.

Dardot e Laval (2016) complementam ao afirmar que devido a pós-democracia conceber tudo como produto passível de ser mercadoria é próxima ao neoliberalismo. Que é antidemocrata já que pauta que o direto privado deveria estar isento de qualquer intervenção, até mesmo do sufrágio universal, desconstruindo os princípios fundamentais da democracia que seriam a participação e o interesse público.

Entretanto, engana-se quem assume que os problemas trazidos pela pós-democracia ocorrem apenas nas esferas políticas e econômicas, o que por si já traz inúmeros problemas a sociedade.

A pós-democracia também atua na área social criando grupos de "individualizados", que segundo Pierra e Dardot (2016, p. 9) é o momento em que os indivíduos são submetidos a um enorme nível de concorrência que afasta aqueles que não alcançarem melhores patamares financeiros, pois "a polarização entre os que desistem e os que são bem sucedidos mina a solidariedade e a cidadania".

Além disso, na pós-democracia deturpa-se o valor veridicidade, pois tudo torna-se parte de uma verdade trazida pelos princípios do neoliberalismo, e segundo Casara (2017) apenas tem por finalidade atender aos valores do mercado e não guarda relação com o que é real para a sociedade, essa verdade que apenas representa os interesses é nomeada de pós-verdade.

Antes de analisar o fenômeno da pós-verdade de forma mais profunda, concebe-se o exame do vocábulo verdade por Bauman (1998) que define como sendo o símbolo de uma utilização, mais precisamente significa uma atitude que é tomada. Sendo que deseja-se que os demais também acreditem e tratem aquilo como verdade, pois as teses apresentadas serão utilizadas como verdades/crenças com forte aprovação, a ponto de serem refutadas ideias que são diferentes daquelas conhecidas. 
Já no conceito de pós-verdade, possui uma conotação mais individual, uma vez que diferente dos preceitos ditos por Joseph Goebbels, ministro da propagando de Adolf Hitler, que tinha como máxima que: "uma mentira dita por mil vezes se tornará uma verdade" (ARANTES, 2017, p. 6). Na pós-verdade há uma combinação correlata de interpretações plausíveis, fontes confiáveis e uma mistura que é absolutamente falsa. Como assevera Dunker (2018) não é a condição de fazer com que se acredite em uma mentira impossível, mas a relação de explorar preconceitos que o interlocutor já possui e que de forma gradual confirma a informação que recebe.

Conforme Dunker (2018) a pós-verdade cria um nicho de informação dos que pertencem a um mesmo grupo e ao qual o indivíduo tem intimidade. Em que as informações introduzidas pelo grupo são tratadas como verdadeiras e a todos que estão fora deste meio apenas cabe a indiferença.

Para Bitencourt e Reck (2019) este termo pode ser definido como uma verdade derivada de crenças e de ideologias, em que não há fatos que podem caracterizar essas informações. E que na pós-verdade é perceptível que há uma despreocupação quando a fundamentação do conhecimento e das notícias.

Enfatiza Sant'Anna (2018) que a pós-verdade na conotação do acesso à informação traz intempéries ainda mais agressivas a sociedade, porque a proliferação das informações tidas por verdadeiras muitas vezes se remeterá a informações que eram de cunho da Administração Pública divulgar de forma oficial. E ao invés disto estão sendo disseminadas por grupos que não possuem o conhecimento das informações divulgadas apenas a sua opinião embasada em pré-conceitos, o que se traduz em um dos ardis da pós-verdade: a falta de informação e/ou o desinteresse da população por aquilo que se refere ao Estado.

Por que segundo Bitencourt e Reck (2019) devido a essa característica de ausência de fatos para compor uma verdade, os cidadãos têm suas informações baseadas na religião/superstição, e não procurando maiores informações para que possa compreender que a verdade se tornou fruto da vontade individual. E sendo perceptível que essas informações disseminadas partem da ideologia de seus portadores.

Para Bitencourt (2019, p. 119) no contexto atual é nítido que há "próteses de pensamentos", que seriam ideias e crenças que vem através da utilização da televisão, telefones e uso em demasia das redes sociais, em que o cidadão passou a aceitar de forma passiva e acrítica. Afirma a autora que "diante do excesso de informação ou a distorção da informação, vê-se crescer de forma quase descontrolada a desinformação".

Volkoff (2004, p. 107) determina que a divulgação das desinformações não se remete a inteligência do público-vivo, mas muito mais a sensibilidade do cidadão, porque para o autor no ser humano "as paixões sempre foram muito mais fortes que as convicções".

Arante (2017) traz um dos exemplos desse colapso de informações da pós-verdade que já ocorrem de forma internacional. Sendo um deles a saída da Inglaterra do Bloco da União Europeia por meio da realização de um referendo para a população votar na decisão de sair ou não do bloco europeu. Contudo alguns dias antes do referendo disseminaram-se informações que essa conexão da Inglaterra com a União Europeia custava milhões aos cofres públicos e que após a saída os valores seriam alocados na saúde.

Clara inverdade disseminada por partidos que desejavam a saída do bloco, visto que não foi considerado os altos investimentos do bloco europeu em educação no país inglês.

Antonhy Downs (1999) realiza um trabalho sobre a possibilidade de voto e a condição para o cidadão atingir a melhor forma de exercer o sufrágio, no entanto o trabalho do autor esbarra na condição da incerteza, 
explana que essa incerteza é baseada na ausência de informações e na falta de segurança informativa para que o agente possa embasar seus conceitos para realizar o voto.

Observa-se que para um cidadão realmente exercer sua vontade em uma democracia, isso no contexto de formulação de políticas públicas, não basta apenas ter conhecimento prévio de informações difundidas em redes sociais ou mídias não oficias e que não prezam pela veracidade, mas conforme Sant'Anna (2018) é necessário que busque muitos mais por informações através de mecanismos oficiais da Administração Públicas para disponibilização de informação.

Apenas a partir da busca de informações e da exposição dessas como medida ideal é que os cidadãos terão acesso à informação e a partir de então poderão exercer o controle social da Administração, não reagindo a dados de fontes desconfiáveis que apenas buscam aludir a vontade dos políticos e governantes.

Porque como bem retrata Arantes (2017) não existe democracia quando a manipulação de dados e da sociedade fala mais alto que o grito da participação popular, o que proporcionará a utilização do poder e dos interesses próprios através de escusas.

\section{CONSIDERAÇÕES FINAIS}

A democracia é um governo do povo, representado na Constituição Federal, devido a isso seus princípios cabem explicitamente à população, e sendo um destes o acesso à informação. Na sociedade atual o acesso à informação é uma via tão importante para a população, porque é onde todos os outros direitos podem ser conhecidos e a forma com que os cidadãos poderão exercer a soberania sobre o Estado.

A soberania construída a partir do acesso à informação tem como uma de suas finalidades principais o controle social, principalmente fazer com que o governo compreenda a importância da atuação da população em velar pelos atos públicos.

E que a partir de uma sociedade que busque informações da Administração Pública e efetivamente fiscalize possa-se ver mais atos corretos e boas alocações dos cofres públicos. Havendo a diminuição de atos e medidas que apenas tenham como interesse individual do governante em prol de determinados grupos.

Todavia, todos estes esforços da busca de informação, da transparência do Estado e da realização do controle social se perdem perante os interesses do Estado pós-democrático e da pós-verdade. Já que um Estado que não mais se interessa pela realização do social, e sim em aceitar os interesses do mercado faz com que a população perca muito do poder de fiscalização.

Como resultados do presente trabalho pode-se observar que devido à disseminação de informações em redes sociais, e o contexto de pós-verdade em que o cidadão é acrítico quanto à verdade dos fatos, não terá como fiscalizar se os governantes estão sendo probos quando ao tratamento do orçamento público.

Esta ausência de informações corretas irá prejudicar a possibilidade de controle social, já que um mecanismo baseada na informação que a população possui. Se forem incoerentes será impossível ao cidadão requerer dos entes públicos melhoria em determinado bairro ou entidade por desconhecer se o munícipio teria ou não orçamento para esta realização.

Esse conhecimento do indivíduo baseado em pseudoverdades e crenças levará a uma participação social que pode trazer prejuízos a comunidade como a situação do Brexit em que informações incoerentes causaram a 
manifestação da população para saída do país da União Europeia. E isto porque diante da pós-verdade os cidadãos tem como informações seu egocentrismo e suas crenças.

A pós-verdade obscurece a possibilidade de acesso à informação, já que os principais sujeitos recebedores dessa informação muitas vezes não querem crer no que é repassado por organismos oficiais, impossibilitando que haja qualquer forma de controle social que possa ser efetivo e trazer melhorias a coletividade.

Por fim, apenas resta ressaltar que enquanto não houver uma Administração presente e que tenha interesse em desmistificar essas informações baseadas apenas em crenças, o cidadão continuará alienado a informações distorcidas e que apenas consentem naquilo que uma elite quer. E que necessita para realizar seus próprios interesses com a máquina pública e não os da sociedade, usando desses subterfúgios até mesmo para distorcer o exercício do controle social da população.

\section{REFERÊNCIAS}

ABRAMO, C. W. Acesso à informação e eficiência do Estado. Revista do Governo. Acesso em: 25 jan. 2018

ARANTES, Bruno Rocha. Democracia na contemporaneidade, uma abordagem sobre a pós-verdade. Revista Jurídica Verba Legis, n. XII, 2017, sem p. Disponível em: < http://apps.tre-go.jus.br/internet/verbalegis/2017/Artigos-03_Democracia-na-contemporaneidade-uma-abordagem-sobre-a-pos-verdade.php\#nota08> Acesso em: 20 mar. 2019.

ARAUJO, Marcelo; SANCHEZ, Oscar Adolfo. A corrupção e os controles internos do estado. Lua Nova: São Paulo , n. 65, p. 137-173. 2005. Disponível em: http://www.scielo.br/scielo.php?script=sci_arttext\&pid=S010264452005000200006\&lng=en\&nrm=iso> Acesso em: 19 mar. 2019.

BALLESTRIN, Luciana. 0 debate pós-democrático no século XXI. Revista Sul-Americana de Ciência Política, v.4, n. 2, 149-164, 2018. Disponível em: <https://periodicos.ufpel.edu.br/ojs2/index.php/rsulacp/article/view/14824> Acesso em: 20 mar. 2019.

BARCELLOS, A. P. Papéis do Direito Constitucional no fomento do controle social democrático: algumas propostas sobre o tema da informação. Revista Direito do Estado. Rio de Janeiro: Renovar, n. 12. p. 77 - 106. Acesso em: 19 mar. 2019.

BEBER, Augusto; BITENCOURT, Caroline Müler. O controle social a partir do modelo de gestão pública compartida: da insuficiência da representação parlamentar à atuação dos conselhos populares como espaços públicos da interação comunicativa. Revista de Direito Econômico e Socioambiental, Curitiba, v. 6, n. 2, p. 232-253. jul/dez. 2015.

BAUMAN, Zigmunt. Modernidade Líquida. Rio de Janeiro: Zahar, 2001.

0 mal estar da pós-modernidade. Rio de Janeiro: Zahar, 1998.

BRASIL. Constituição da República Federativa do Brasil, $1988 . \quad$ Disponível em: <http://www.planalto.gov.br/ccivil_03/Constituicao/Constituicao.htm> Acesso em: 12 jul. 2017.

BITENCOURT, Caroline Müller. Acesso à Informação para o exercício do controle social: desafios a construção da cultura de transparência no Brasil e diretrizes operacionais e legais para os portais no âmbito municipal. No prelo.

BITENCOURT, Caroline Müler; RECK, Janriê. Interações entre o direito fundamental à informação e democracia para o controle social de uma leitura crítica da LAI. Revista Direitos Fundamentais \& Democracia, Curitiba, v. 23, n.3, p. 123-156, set/dez. 2018. Disponível em: Acesso em: 10 abr. 2019. 
Direito Administrativo e seu diagnóstico de seu tempo no Brasil. A \& C - Revista de Direito Administrativo \& Constitucional. Belo Horizonte, n. 75, p. 241- 264, jan./mar. 2019. Disponível em: Acesso em 24 maio 2019.

CANELA, G.; NASCIMENTO, S (Orgs.). Acesso à informação e controle social das políticas. Brasília: ANDI; Artigo 19, 2009. Disponível em: <http://www.andi.org.br/politicas-de-comunicacao/publicacao/acesso-a-informacao-econtrole-social-das-politicas-publicas >. Acesso em: 2 jan. 2019.

CASARA, Rubens. Estado pós-democrático: neo-obscurantismo e gestão dos indesejáveis. Rio de Janeiro: Civilização Brasileira, 2017.

CASTELLS, Manuel. A sociedade em rede. São Paulo: Editora Paz e Terra, 1999.

DARDOT, Pierre; LAVAL, Christian. A nova razão do mundo: ensaio sobre a sociedade neoliberal. São Paulo: Boitempo, 2016.

DI PIETRO, Maria Sylvia Zanella. Direito Administrativo, São Paulo: Altas, 2016

DOWNS , Antonhy. Uma teoria econômica da democracia. São Paulo: Editora Universidade de São Paulo, 1999.

DUNKER, Cristian. Subjetividade em tempos de pós-verdade. In: DUNKER et al. Ética e pós-verdade. Porto Alegre, RS: Editora Dublinense, 2017.

FAGUNDES, Tatiana Penharrubia. 0 controle social das contas municipais. Tese (Doutorado em Direito) Universidade de São Paulo: São Paulo, 2012.

GRUMAN, Marcelo. Lei de Acesso à Informação: notas para reflexão e um breve exemplo. Revista Espaço Acadêmico, n. 141, p. 90-99, fev. 2013. Disponível em: www.periodicos.uem.br/ojs/index.php/EspacoAcademico/article/viewFile/18873/10406. Acesso em: 2 jan. 2019

JARDIM, José Maria. Transparência e opacidade do Estado: usos e desusos da informação governamental. Niterói, RJ: Editora da Universidade Federal Fluminense, 1999.

MENDEL, Toby. Liberdade de informação: um estudo de direito comparado. 2. ed. Brasília: UNESCO, 2009.

PRATA, Nilson Vidal. Informação e Democracia deliberativa: um estudo de caso de participação política na Assembleia Legislativa do Estado de Minas Gerais. Dissertação (Mestrado em Ciência da Informação) Universidade Federal de Minas Gerais, Belo Horizonte, 2007.

SAITO, Camila Yumy. Sistemas de rankings para avaliação de políticas públicas e redução de assimetria de informação na decisão do voto. Dissertação (Mestrado Profissional em Finanças e Economia) - Fundação Getúlio Vargas, São Paulo, 2016.

SANT'ANNA, Marilia Mendonça Morais. Transparência e Controle Social da Administração Pública: Limites e Possibilidades no cenário brasileiro. Tese (Doutorado em Direito Político e Econômico) - Universidade Presbiteriana Mackenzie: São Paulo, 2018.

SECCHIN, Lenise Barcellos de Mello. Controle Social: transparência das políticas públicas e fomento ao exercício de cidadania. In: Revista da CGU, ano III- $\mathbf{N}^{\circ} 5$, dezembro de 2008 . Disponível em: <http://www.cgu.gov.br/publicacoes/revistacgu/Arquivos/5edicao.pdf> Acesso em: 30 fev. 2019.

SIRAQUE, Vanderlei. Controle Social da Função Administrativa do Estado: Possibilidade e Limitações na Constituição de 1998. Dissertação (Mestrado em Direito) - Pontifica Universidade Católica de São Paulo: São Paulo, 2004.

Tribunais de Contas para o Controle Social (Carvalho e Albuquerque).

VOLKOFF , Vladimir. Pequena história da desinformação: do cavalo de Tróia à Internet. Curitiba: Vila do Príncipe, 2004. 
ZENI, Bruna Schlindwein. Conselhos Municipais: efetivamente um instrumento democrático deliberativo: uma análise do Conselho Municipal dos Direitos da Mulher da Cidade de Santa Cruz do Sul/RS. 2010.143 f. Dissertação (Mestrado em Direito) - Universidade de Santa Cruz do Sul, 2011. 